\title{
Pengaruh Model Pembelajaran Anchored Instruction terhadap Penguasaan Konsep dan Kemampuan Pemecahan Masalah Fisika Siswa Kelas X
}

\author{
Ellyna Hafizah, Arif Hidayat, Muhardjito \\ Prodi Pendidikan Fisika, Pascasarjana, Universitas Negeri Malang \\ Jl. Semarang No. 5 Malang \\ ellyna0309@gmail.com
}

\begin{abstract}
Abstrak - Penelitian ini bertujuan untuk mengetahui pengaruh model pembelajaran anchored instruction terhadap penguasaan konsep dan kemampuan pemecahan masalah Fisika. Penelitian ini merupakan penelitian kuasi eksperimen menggunakan dua kelas yaitu kelas eksperimen dan kelas kontrol. Populasi penelitian ini adalah seluruh kelas X MAN 2 Martapura semester genap tahun ajaran 2013/2014. Sampel terdiri atas kelas eksperimen dan kelas kontrol yang dipilih secara acak. Kelas eksperimen belajar menggunakan anchored instruction dan kelas kontrol belajar menggunakan inkuiri terbimbing. Pembelajaran dilakukan pada materi suhu dan kalor. Data yang didapatkan dianalisis menggunakan multivariate of anova. Pengaruh pembelajaran diuji dengan uji Tukey. Hasil analisis menunjukkan penguasaan konsep dan kemampuan pemecahan masalah Fisika kelas eksperimen lebih baik daripada kelas kontrol.
\end{abstract}

Kata kunci: anchored instruction, penguasaan konsep, kemampuan pemecahan masalah Fisika

\begin{abstract}
The research goal is to exam the influence of the anchored instruction model on student's conceptual understanding and problem solving ability of Physics. This research is a quasi-experimental study with two samples consist of treatment class and control class. The population of research are second semester X grade students of MAN 2 Martapura in the academic year 2013/2014. The samples consist of treatment class and control class that were randomly selected. The treatment class learned by using anchored instruction, while control class learned by using guided inquiry. The learning materials focused on heat and temperature. The data obtained were analyzed by using multivariate of analysis of variance. The effect of learning were analyzed by Tukey's test. The result showed that student's conceptual understanding and problem solving ability of Physics on treatment class is better than the control class.
\end{abstract}

Key words: anchored instruction, conceptual understanding, problem solving

\section{PENDAHULUAN}

Fisika yang merupakan salah satu bagian dari pembelajaran modern yang mempunyai tujuan agar siswa dapat belajar secara efektif dan menggunakan pengetahuannya untuk menganalisis situasi yang berkenaan dengan fisika. Pembelajaran interaktif dan inovatif merupakan salah satu jawaban yang dapat digunakan untuk menghadapi tuntutan pembelajaran modern saat ini. Mengingat tujuan akhir mengajar adalah membantu siswa agar dapat menjadi pelajar yang mandiri dan self-regulated [1]. Hal ini membuat pembelajaran bukan hanya mengenai fakta yang diajarkan tapi bagaimana menguasai konsep [2].

Tantangan masa depan atau pembelajaran modern sendiri tidak hanya menuntut siswa menguasai konsep namun juga mengembangkan keterampilan berpikir. Salah satu keterampilan berpikir yang dapat dikembangkan menurut [3] adalah proses berpikir termasuk kemampuan pemecahan masalah. Kemampuan pemecahan masalah merupakan sebuah proses kognitif yang meliputi langkah penyelesaiaan untuk mendapatkan jawaban [4].
Salah satu materi fisika yang memerlukan penguasaan konsep dan keterampilan pemecahan masalah adalah materi suhu dan kalor. Suhu dan kalor adalah materi yang sering terjadi kesalahan konsep pada siswa dalam pembelajaran yang dilakukan guru [5,6]. Materi suhu dan kalor akan lebih mudah dipahami ketika materi tersebut dapat disajikan pada permasalahan sehari-hari.

Pembelajaran materi suhu dan kalor selama ini hanya diajarkan bagaimana konsep-konsep yang terdapat dalam materi tersebut secara abstrak. Tanpa melibatkan lebih jauh pengetahuan yang siswa miliki untuk menyelesaikan permasalahan sehari-hari secara lebih nyata dan natural untuk meningkatkan kemampuan berpikir siswa [6]. Dalam pembelajaran materi suhu dan kalor, sebagian guru mengalami kendala bagaimana cara menanamkan konsep secara tepat dalam diri siswa. Sehingga sebagian siswa beranggapan bahwa antara suhu dan kalor sama, alat ukur yang digunakan untuk mengukur suhu dan kalor juga dianggap sama [5].

Berdasarkan karakteristik materi suhu dan kalor diperlukan suatu pembelajaran yang langsung menghadapkan siswa pada kenyataan sehingga penguasaan konsep dan kemampuan pemecahan masalah siswa dapat dilatihkan. Hal ini didukung dari hasil 
pengamatan dan wawancara dengan guru yang menyatakan bahwa materi suhu dan kalor akan lebih efektif jika diajarkan dengan menyajikan masalah secara langsung dan didukung dengan penyelidikan oleh siswa. Karena selama ini siswa MAN 2 Martapura jarang diajarkan dengan model pembelajaran yang langsung menghadapkan siswa pada masalah dengan dunia nyata. Meskipun pada materi suhu dan kalor guru telah berusaha mengajak siswa melakukan penyelidikan atau praktikum namun kurang dari 50\% siswa yang memahami makna dari praktikum yang telah dilakukan. Kebanyakan hanya mengikuti instruksi yang tertera dalam lembar kerja tanpa memahami dan menguasai konsep yang terkandung dalam kegiatan tersebut.

Melihat karakteristik materi dan kenyataan yang ada dilapangan, perlu adanya suatu model pembelajaran bermakna yang interaktif dan terstruktur agar konsepkonsep yang disampaikan tertanam dalam memori jangka panjang siswa. Salah satu bentuk model pembelajaran bermakna yaitu Anchored Instruction (AI).

Model pembelajaran AI secara umum mirip dengan model pembelajaran Problem Based Learning (PBL). Namun keduanya tetap memiliki perbedaan, dalam PBL siswa diharapkan melakukan dan mencari sumber informasi yang terkait dalam pembelajaran sendiri. Sedangkan model pembelajaran AI mempunyai tipe menempelkan semua informasi yang diperlukan untuk pemecahan masalah dalam bentuk "anchor" (dapat berupa video atau teknologi multimedia interaktif lain) yang telah disajikan, menekankan pada penggunaan multimedia (terutama yang bersifat visual) dalam penyajian "anchor", memberikan kemudahan mengatur pembelajaran dengan waktu dan sumber pembelajaran yang terbatas [7]. Model AI juga memungkinkan siswa dan guru untuk saling berbagi perspektif dari suatu pengalaman secara kooperatif [8]. Sehingga model pembelajaran AI merupakan salah satu model yang dapat meningkatkan keaktifan siswa dalam lingkungan belajar berbasis masalah.

Model pembelajaran AI memiliki beberapa keuntungan dibandingkan model pembelajaran lain. Menurut [9] keuntungan tersebut antara lain siswa dapat menjadi pemecah masalah sendiri, mengembangkan pemahaman secara mendalam, meningkatkan kemungkinan untuk mentransfer pengetahuan pada situasi yang berbeda, meningkatkan kemampuan kolaboratif, kooperatif dan negosiasi siswa. Pembelajaran menjadi lebih efektif ketika guru menggunakan multimedia (dapat berupa powerpoint) untuk menghubungkan teori kognitif yang dimiliki siswa dengan lingkungan pembelajaran berbasis masalah dibandingkan pembelajaran secara tradisonal [10,11]. Penggunaan web sebagai salah satu bantuan dalam pembelajaran AI juga memberikan hasil yang positif dalam peningkatan potensial siswa dalam memahami konsep pelajaran, memecahkan masalah serta penggunaan waktu dalam perencanaan pemecahan masalah [12].
Penelitian ini dilakukan untuk mengetahui penguasaan konsep dan kemampuan pemecahan masalah yang lebih tinggi antara siswa yang belajar dengan model pembelajaran AI dan inkuiri terbimbing. Adapun hipotesis penelitian ini adalah terdapat perbedaan penguasaan konsep dan kemampuan pemecahan masalah fisika siswa yang belajar dengan model pembelajaran AI dan inkuiri terbimbing. Penguasaan konsep siswa lebih tinggi belajar dengan AI daripada yang belajar dengan inkuiri terbimbing. Kemampuan pemecahan masalah fisika lebih tinggi siswa yang belajar dengan AI daripada yang belajar dengan inkuiri terbimbing.

Langkah-langkah pembelajaran AI yang digunakan dalam penelitian ini mengadaptasi dari langkah-langkah yang dikemukakan dalam [13] yaitu: menjelaskan atau memperkenalkan "anchor", mengembangkan pengalaman, mengembangkan solusi dengan melakukan penelitian, menggunakan pengetahuan, menyelesaikan permasalahan, mengkomunikasikan dan mempresentasikan hasil.

Pengukuran penguasaan konsep dalam penelitian ini merujuk pada indikator dalam pencapain konsep berdasarkan taxonomi Bloom yang direvisi dalam [14] yaitu mengingat, memahami, menerapkan, menganalisis, mengevaluasi, dan menciptakan/ membuat. Sedangkan kemampuan pemecahan masalah dalam penelitian ini diukur dengan memperhatikan variabel-variabel yang terkandung dalam kemampuan pemecahan masalah yang dikembangkan dalam [15] dan [16]. Adapun variabelvariabel yang terkandung dalam kemampuan masalah yang diukur dalam penelitian ini disajikan dalam Tabel 1.

\section{METODE PENELITIAN}

Penelitian ini merupakan penelitian kuasi eksperimen dengan menggunakan dua kelas yaitu satu kelas eksperimen dan satu kelas kontrol. Kelas eksperimen adalah kelas yang belajar dengan model pembelajaran AI sedangkan kelas kontrol adalah kelas yang belajar dengan inkuiri terbimbing. Pokok bahasan yang diteliti adalah suhu dan kalor. Desain penelitian menggunakan posttest only control group design.

Populasi dalam penelitian ini adalah siswa kelas $\mathrm{X}$ MAN 2 Martapura pada semester genap tahun ajaran 2013/2014 yang terdiri atas enam kelas yaitu kelas X1, X2, X3, X4, X5 dan X6 dengan jumlah 192 siswa, dengan jumlah siswa tiap kelas 32 siswa. Sampel dipilih secara acak dan terpilih kelas X1 sebagai kelas eksperimen dan kelas X2 sebagai kelas kontrol.

Instrumen perlakuan meliputi Silabus, RPP, dan LKS dibuat dan dilakukan validasi oleh dua orang dosen. Penguasaan konsep siswa diukur dengan menggunakan instrumen tes yang berupa soal pilihan ganda sebanyak 12 soal. Kemampuan pemecahan masalah fisika siswa diukur dengan menggunakan instrumen tes yang berupa soal essai sebanyak 4 soal. Kedua instrumen pengukuran sebelumnya telah divalidasi isi oleh dua orang dosen dan dilakukan uji coba untuk menentukan validitas dan 
reliabilitasnya. Tes penguasaan konsep dan kemampuan pemecahan masalah fisika siswa diperoleh dari hasil postes yang dilakukan setelah pokok bahasan suhu dan kalor selesai.

Analisis data dilakukan dengan menggunakan multivariate of analysis of varians. Sebelum dilakukan pengujian hipotesis data dilakukan uji prasyarat, yaitu: uji normalitas, uji homogenitas varians, uji homogenitas varians-kovarians, dan uji linearitas.

Tabel 1. Sub variabel kemampuan pemecahan masalah[15,16].

\begin{tabular}{|c|c|c|c|}
\hline $\begin{array}{c}\text { Varia } \\
\text {-bel }\end{array}$ & $\begin{array}{c}\text { Sub } \\
\text { varia- } \\
\text { bel }\end{array}$ & Indikator & Kegiatan siswa \\
\hline \multirow[t]{4}{*}{$\begin{array}{l}\text { Ke- } \\
\text { mam- } \\
\text { puan } \\
\text { peme- } \\
\text { cahan } \\
\text { masa- } \\
\text { lah }\end{array}$} & $\begin{array}{l}\text { Analo } \\
\text {-gi }\end{array}$ & $\begin{array}{l}\text { Memecahkan } \\
\text { masalah untuk } \\
\text { nilai yang dapat } \\
\text { dipandang secara } \\
\text { umum sebagai } \\
\text { hasil dari } \\
\text { menganalogi/ } \\
\text { digeneralisasi }\end{array}$ & $\begin{array}{l}\text { Menyimpulkan suatu } \\
\text { hasil penyelesaian } \\
\text { masalah yang dapat } \\
\text { digeneralisasi atau } \\
\text { dinilai sebagai } \\
\text { penyelesaian yang } \\
\text { dipandang secara } \\
\text { umum }\end{array}$ \\
\hline & $\begin{array}{l}\text { Argu- } \\
\text { menta } \\
\text {-si }\end{array}$ & $\begin{array}{l}\text { Merduksi } \\
\text { penjelasan dengan } \\
\text { berargumentasi } \\
\text { menjadi lebih } \\
\text { sederhana/ secara } \\
\text { potensial } \\
\text { menyerderhana- } \\
\text { kan dan tidak } \\
\text { menggunakan hal- } \\
\text { hal yang tidak } \\
\text { diperlukan }\end{array}$ & $\begin{array}{l}\text { Menganalisis faktor } \\
\text { dari setiap masalah } \\
\text { untuk mereduksi } \\
\text { permasalahan } \\
\text { sehingga dapat } \\
\text { menentukan faktor } \\
\text { yang memperngaruhi }\end{array}$ \\
\hline & $\begin{array}{l}\text { Model } \\
\text {-ing }\end{array}$ & $\begin{array}{l}\text { Merakit fakta } \\
\text { tentang kesulitan } \\
\text { dalam bentuk } \\
\text { pemodelan }\end{array}$ & $\begin{array}{l}\text { Merangkum masalah } \\
\text { dalam bentuk model } \\
\text { (grafik atau gambar) }\end{array}$ \\
\hline & $\begin{array}{l}\text { Kau- } \\
\text { sal }\end{array}$ & $\begin{array}{l}\text { Menggunakan } \\
\text { proses berpikir } \\
\text { dasar untuk } \\
\text { mengatasi } \\
\text { kesulitan yang } \\
\text { telah diketahui } \\
\text { melalui hubungan } \\
\text { sebab akibat }\end{array}$ & $\begin{array}{l}\text { Menggunakan proses } \\
\text { berpikir dasar untuk } \\
\text { mengatasi masalah } \\
\text { sebab akibat }\end{array}$ \\
\hline
\end{tabular}

\section{HASIL DAN PEMBAHASAN}

Selama proses pembelajaran berlangsung dilakukan observasi keterlaksanaan proses pembelajaran oleh dua orang observer. Adapun persentase keterlaksanaan pembelajaran dapat dilihat pada Tabel 1.

Tabel 2. Persentase Keterlaksanaan Proses Pembelajaran.

\begin{tabular}{|c|c|c|c|c|c|c|c|c|c|c|}
\hline \multirow{3}{*}{$\begin{array}{l}\mathrm{Ke}- \\
\text { las }\end{array}$} & \multicolumn{8}{|c|}{ Pertemuan } & \multirow{2}{*}{\multicolumn{2}{|c|}{ Rata-rata }} \\
\hline & \multicolumn{2}{|c|}{1} & \multicolumn{2}{|c|}{2} & \multicolumn{2}{|c|}{3} & \multicolumn{2}{|c|}{4} & & \\
\hline & G & $\mathrm{S}$ & G & $\mathrm{S}$ & G & $\mathrm{S}$ & G & $\mathrm{S}$ & G & $\mathrm{S}$ \\
\hline $\mathrm{E}$ & 84 & 82 & 91 & 87 & 88 & 87 & 94 & 89 & 89 & 86 \\
\hline K & 78 & 73 & 92 & 88 & 91 & 90 & 91 & 87 & 88 & 84 \\
\hline
\end{tabular}

\section{Keterangan:}

E : Eksperimen (anchored instruction)

$\mathrm{K}$ : Kontrol (inkuiri terbimbing)
G : Guru

S : Siswa

Berdasarkan persentase pada Tabel 2 menunjukkan bahwa siswa dan guru pada kelas eksperimen dan kontrol secara keseluruhan semakin memahami proses pembelajaran dari pertemuan ke pertemuan berikutnya. Sehingga dapat dikatakan bahwa penguasaan konsep dan kemampuan pemecahan masalah fisika siswa terjadi akibat proses pembelajaran ini.

Data penguasaan konsep dan kemampuan pemecahan masalah fisika siswa diperoleh melalui tes pada akhir penelitian. Sebelum dilakukan pengujian hipotesis, kedua data tersebut dilakukan uji prasyarat seperti uji normalitas, uji homogenitas varians, uji homogenitas varians-kovarians, dan uji linieritas. Hasil uji normalitas yang dilakukan dengan uji liliefors mendapatkan untuk penguasaan konsep dan kemampuan pemecahan masalah pada kelas eksperimen dan kontrol data terdistribusi normal. Data bersifat homogen saat diuji sendiri-sendiri dan homogen saat diuji bersama-sama. Kedua data juga bersifat linear.

Kedua data penguasaan konsep dan kemampuan pemecahan masalah setelah dilakukan uji prasyarat dilanjutkan pengujian hipotesis pertama dengan menggunakan uji manova. Hasil pengujian manova dapat dilihat pada Tabel 3. Uji manova menunjukkan hasil (sig $0,00<\alpha$ ) ini berarti $\mathrm{H}_{0}$ ditolak dan $\mathrm{H}_{1}$ diterima bahwa terdapat perbedaan penguasaan konsep dan kemampuan pemecahan masalah siswa yang belajar dengan AI (kelas eksperimen) dan inkuiri terbimbing (kelas kontrol).

Hipotesis kedua dilakukan pengujian dengan uji Tukey. Hasil uji Tukey menunjukkan bahwa siswa yang belajar dengan AI (kelas eksperimen) memiliki penguasaan konsep yang lebih tinggi dibandingkan siswa yang belajar dengan inkuiri terbimbing (kelas kontrol). Nilai rata-rata penguasaan konsep kedua kelas ditunjukkan oleh diagram pada Gambar 1.

Tabel 3. Data hasil uji manova.

Multivariate Tests ${ }^{\mathrm{D}}$

\begin{tabular}{|c|c|c|c|c|c|c|}
\hline \multicolumn{2}{|l|}{ Effect } & Value & $\mathrm{F}$ & Hypothesis df & Error df & Sig. \\
\hline \multicolumn{2}{|c|}{ Intercept Pillai's Trace } & .993 & $4.119 \mathrm{E} 3^{\mathrm{a}}$ & 2.000 & 61.000 & .000 \\
\hline & Wilks' Lambda & .007 & $4.119 \mathrm{E} 3^{\mathrm{a}}$ & 2.000 & 61.000 & .000 \\
\hline & Hotelling's Trace & 135.056 & $4.119 \mathrm{E} 3^{\mathrm{a}}$ & 2.000 & 61.000 & .000 \\
\hline & Roy's Largest Root & 135.056 & $4.119 \mathrm{E} 3^{\mathrm{a}}$ & 2.000 & 61.000 & .000 \\
\hline \multirow[t]{4}{*}{ Kelas } & Pillai's Trace & .326 & $14.737^{\mathrm{a}}$ & 2.000 & 61.000 & .000 \\
\hline & Wilks' Lambda & .674 & $14.737^{\mathrm{a}}$ & 2.000 & 61.000 & .000 \\
\hline & Hotelling's Trace & .483 & $14.737^{\mathrm{a}}$ & 2.000 & 61.000 & .000 \\
\hline & Roy's Largest Root & .483 & $14.737^{\mathrm{a}}$ & 2.000 & 61.000 & .000 \\
\hline
\end{tabular}

a. Exact statistic

b. Design: Intercept + Kelas 


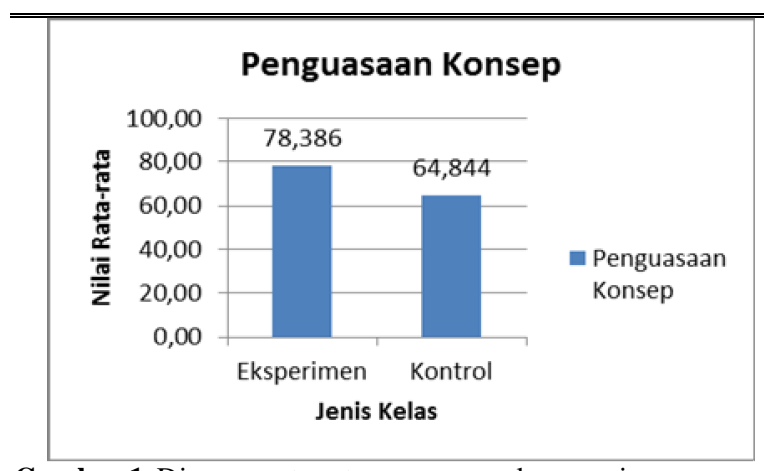

Gambar 1. Diagram rata-rata penguasaan konsep siswa.

Berdasarkan diagram pada Gambar 1 terlihat bahwa penguasaan konsep pada kelas eksperimen lebih tinggi daripada kelas kontrol. Hal ini menandakan model pembelajaran AI dapat mempengaruhi peningkatan penguasaan konsep siswa seperti apa yang telah diungkapkan Impedovo (2009) dan Chu (2011) bahwa AI memberikan hasil yang positif dalam peningkatan potensial siswa dalam memahami konsep pelajaran.

Hipotesis ketiga juga dilakukan pengujian dengan uji Tukey. Hasil uji Tukey menunjukkan bahwa siswa yang belajar dengan AI (kelas eksperimen) memiliki kemampuan pemecahan masalah yang lebih tinggi dibandingkan siswa yang belajar dengan inkuiri terbimbing (kelas kontrol). Nilai rata-rata kemampuan pemecahan masalah kedua kelas ditunjukkan oleh diagram pada Gambar 2.

Diagram yang ditunjukkan Gambar 2 memberikan arti bahwa model pembelajaran AI dapat meningkatkan kemampuan pemecahan masalah siswa. Hal ini sejalan dengan apa yang disampaikan Kovalchick (2004) bahwa pembelajaran AI dapat memberikan keuntungan. Keuntungan tersebut siswa mampu menjadi pemecah masalah sendiri dengan mengembangkan pemahaman secara mendalam melalui masalah yang telah dikemas sedemikian rupa diawal pembelajaran dan hasil kolaborasi siswa dalam diskusi yang dilakukan.

\section{Kemampuan Pemecahan Masalah}

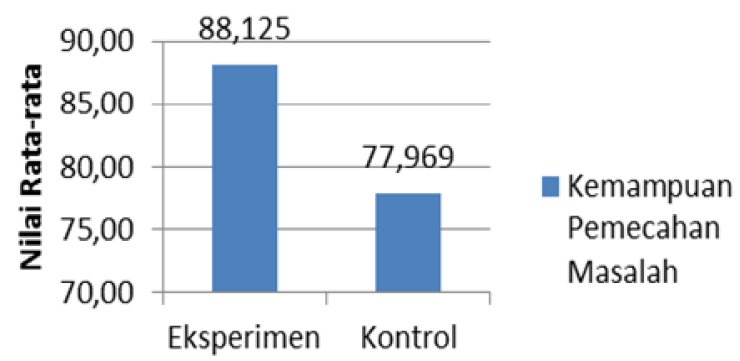

\section{Jenis Kelas}

Gambar 2. Diagram rata-rata kemampuan pemecahan masalah siswa.

\section{KESIMPULAN}

Berdasarkan hasil penelitian dan pembahasan yang telah dilakukan kesimpulan penelitian ini adalah terdapat pengaruh positif yang signifikan dari model pembelajaran AI dan inkuiri terbimbing terhadap penguasaan konsep dan kemampuan pemecahan masalah fisika siswa. Penguasaan konsep siswa yang belajar dengan AI lebih baik daripada siswa yang belajar dengan inkuiri terbimbing. Siswa yang belajar dengan model pembelajaran AI juga mempunyai kemampuan pemecahan masalah yang lebih tinggi daripada siswa yang belajar dengan inkuiri terbimbing.

\section{PUSTAKA}

[1] Arends, R. I. Learning to Teach. Terjemahan Soetjipto, Pustaka Pelajar, 2008.

[2] Madu, B. C. \& Amaechi, C. C. Effect of Five-Step Learning Cycle Model on Students' Understanding of Concepts Related to Elasticity. Journal of Education and Practice, vol. 3, no. 9, 2012, pp. 36-45.

[3] Marzano, Robert. J, dkk. Dimension of Thinking: A Framework for Curriculum and Instruction, ASCD, 1988.

[4] Santrock, J. W. Educational Psychology, Library of Congress Cataloging-in-Publication Data, 2011.

[5] Setyadi, Eko K. Miskonsepsi Tentang Suhu dan Kalor pada Siswa Kelas 1 di SMA Muhammadiyah Purworejo, Jawa Tengah. Berkala Fisika Indonesia, vol. 4, no. 2, 2012, pp. : 46-49.

[6] Baser, Mustafa. Fostering Conceptual Change by Cognitive Conflict Based Instruction on Students' Understanding of Heat and Temperature Concepts. Eurasia Journal of Mathematics, Science and Technology Education, vol. 2, no. 2, 2006, pp. 96-113.

[7] Oliver, Kevin, Anchored Instruction, 1999. Website: http://www.edtech.vt.edu /edtech/id, diakses tanggal 10 Juni 2013.

[8] Love, Mary Susan. Multimodality of Learning Throught Anchored Instruction. Journal of Adolescent \& Adult Literacy, vol. 48, no. 4, 2004, pp. 300-310.

[9] Kovalchick, Ann \& Kara Dawson (Eds). Education and Technology An Encyclopedia, Santa Bara, 2004.

[10] Chen, Yuh-Tyng. Integrating anchored instructional strategy and modularity concept into Interactive multimedia PowerPoint presentation. International Journal of the Physical Sciences, vol. 7, no. 1, 2012, pp. $107-115$.

[11] Kariuki, Mumbi \& Mesut Duran. Using Anchored Instruction to Teach Preservice Teachers to Integrate Technology in the Curriculum. Journal of Technology and Teacher Education, vol. 12, no. 3, 2004, pp. 431-445.

[12] Chu, Ng Kim \& Sau Cheong. Anchored Instruction for Early Vocabulary Learning through Storybook Reading: An Action Research. International Journal of Educational Administration and Development, vol. 2, no. 2, 2011, pp. 48-62.

[13] Baumbach, Donna, Sally Brewer \& Mary Bird. Using Anchored Instruction in Inservise Teacher Education. Technology and Teacher Education Annual, vol. 10, no. 12, 1995, pp. 809-813.

[14] Anderson, L.R. \& Krathwohl, D.R. A Taxonomi for Learning, Teaching and Assessing. A Revision oe Bloom's Taxonomi of Educational Objective, Longman, 2001. 
Pemecahan Masalah Fisika Siswa Kelas X

[15] Costa A.L. Develoving of Mind. A Resourse Book for Teaching Thingking, ASCD publication, 1985.

[16] Jonnasen, D.H. Learning to Solve Problem, Routledge, 2011.

\section{TANYA JAWAB}

Fatkhur Rohman, UAD

? Apakah bisa model pembelajaran AI dapat diterapkan / diaplikasikan poada sekolah yang sarana dan prasarananya belum memadai / belum lengkap?

Ellyna Hafizah, Universitas Negeri Malang

@ Sampai saat ini belum dapat dilakukan karena menekankan pada visualisasi jadi minimal harus sekolah memiliki alat multimedia interaktif

\section{Nurkhamidah, UAD}

? Bagaimana proses pembelajaran menggunakan Anchored Instruction , samakah dengan metode anchored pada NLP?

\section{Ellyna Hafizah, Universitas Negeri Malang}

@ Pada dasarnya hampir sama yaitu menekankan pada visualisasi pada saat pemberian masalah. 